\title{
Separate visual pathways for perception of actions and objects: evidence from a case of apperceptive agnosia
}

\author{
Carla Teixeira Ferreira, Mathieu Ceccaldi, Bernard Giusiano, Michel Poncet
}

\begin{abstract}
Recognition of different kinds of visual stimuli was studied in a patient who acquired apperceptive visual agnosia after a bilateral occipitotemporal lesion which partially spared the primary visual cortex. Impairment in recognising static objects perceived visually sharply contrasts with the relatively well preserved ability to recognise objects from gestures illustrating their use, and to recognise actions shown in line drawings. It is suggested that the occipitoparieto-frontal pathway is involved in the recognition of actions, and in the recognition of objects when sensorimotor experience is evoked. (F Neurol Neurosurg Psychiatry 1998;65:382-385)
\end{abstract}

Keywords: recognition; parietal lobe; frontal lobe

Visual agnosia is the inability to recognise visual stimuli despite adequate elementary visual function. Visually agnosic patients are unable to produce gestures of object use or to show any recognition of the objects they fail to name.

Laboratoire de Neurophysiologie et Neuropsychologie, Upres EA 2200 CJF Inserm 9706, Faculté de Médecine de Marseille, Université de la Méditerranée, France

C T Ferreira

M Ceccaldi

B Giusiano

M Poncet

Department of

Neurology,

Universidade Federal do Rio de Janeiro,

Brasil

C T Ferreira

Correspondence to: Dr Carla Teixeira Ferreira, Rua Bartolomeu Portela, 50/505, Botafogo CEP: 22.290.190, Rio de Janeiro, Brasil. Fax 55.21.542.5071

Received 20 March 1997 and in final revised form 5

February 1998

Accepted 16 February 1998 subsequent recognition. Therefore, the recognition of an object from a static visual presentation of it may essentially involve the occipitoinferotemporal pathway. By contrast, because actions are learned primarily through sensorimotor experience, the recognition of an action represented in a photograph, or the recognition of an object from a visual presentation of a gesture illustrating its use, may chiefly involve the occipitoparietofrontal stream.

\section{Case report}

The patient was a right handed 65 year old retired male engineer. He had a left occipitotemporal haemorrhage in 1981 and a right occipitotemporal haemorrhage in 1991 (fig 1).

His general neurological examination was normal. Neuropsychological assessment disclosed a verbal intelligence quotient of 150 (WAIS), a memory quotient of 85 (Wechsler $\mathrm{R})$, and intact speech (BDAE). He was able to write, but he was forced to use a letter by letter strategy to read. He had complete achromatopsia (Ishiara test), and impaired visual recognition of objects and faces. He exhibited bilateral quadrantanopia (right inferior and left superior quadrants). P100 visual evoked potentials were spared. Visual acuity was normal in the preserved visual fields. His pupillary responses were normal and his voluntary eye movements were complete.

Despite the fact that he could describe a visually perceived object in detail, he failed to relate individual elements to the whole, and consequently, he was not able to identify it. He could produce accurate copies of line drawings of objects by implementing a piecemeal, line by line copying strategy that was extremely slow (for example, he took eight minutes to copy a drawing of a comb). He was unable to match objects seen from different views (13/23). In an object decision task in which he was required to determine whether line drawings corresponded to real objects (Snodgrass and Vanderwart set $^{18}$ ) or to non-objects (Kroll and Potter set ${ }^{19}$ ), his performance was deficient $(31 / 40)$, indicating that his ability to access structural object knowledge through visual presentation was impaired. The utilisation of silhouettes of these same stimuli did not improve performance 
(26/40). His score on Benton's judgment of line orientation test was normal (23/30).

EXPERIMENTAL INVESTIGATION

To investigate the patient's visual object recognition deficit, we compared his object recognition performance in different modes including visual presentation of a static real object, visual presentation of a real object being moved in a non-specific way by the examiner (rotation and horizontal displacement), tactile presentation, verbal definition, examiner pantomime of how the object might be used, and examiner utilisa-
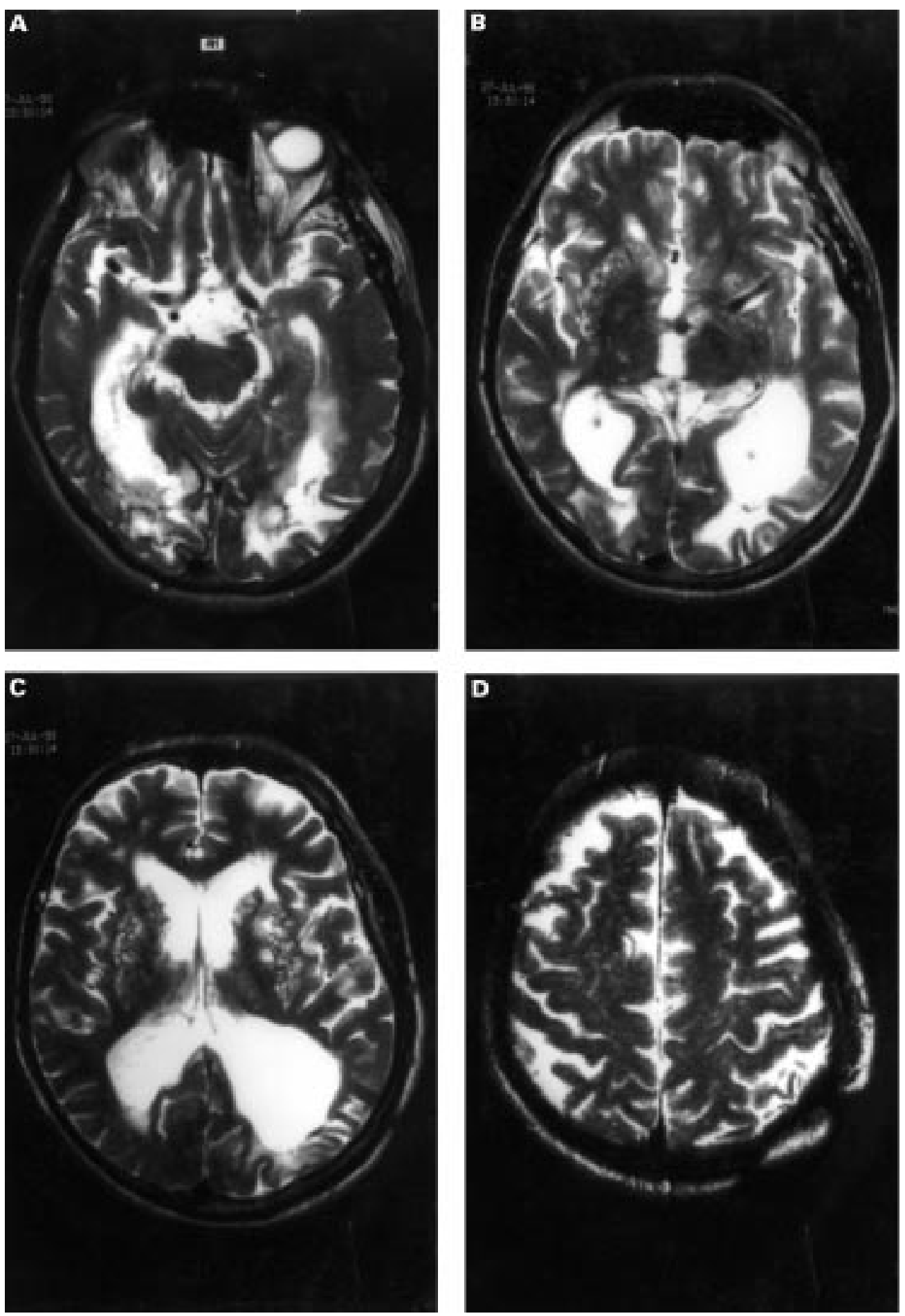

tion of the object. The same set of 30 real objects was used for all tasks. As the table shows, visually presented object recognition was impaired. By contrast, recognising objects on tactile presentation (McNemar symmetry $\left.\chi^{2}=19.0, \mathrm{p}<0.0001\right)$, verbal definition $(\mathrm{McNe}-$ mar symmetry $\left.\chi^{2}=21.0, \mathrm{p}<0.0001\right)$, pantomimes of object use (McNemar symmetry $\left.\chi^{2}=14.2, \mathrm{p}<0.001\right)$, and utilisation of real objects (McNemar symmetry $\chi^{2}=17.0$, $\mathrm{p}<0.0001$ ) were significantly better. These results confirmed that he was particularly

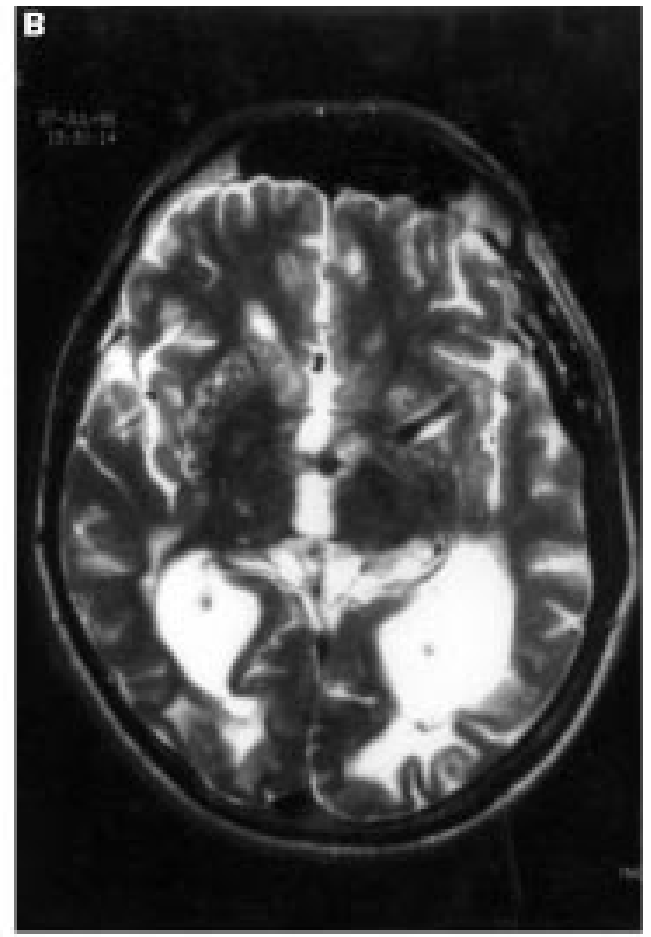

Figure 1 Representative horizontal MRI cross section of the patient. 
Table 1 The patient's results on naming tests

\begin{tabular}{llc}
\hline Type of presentation & Stimuli $(n)$ & $\begin{array}{c}\text { Correct responses } \\
(n(\%))\end{array}$ \\
\hline Visual, real objects: & 30 & $7(23)$ \\
Static & 30 & $3(10)$ \\
Non-specific movement & 30 & $26(87)$ \\
Tactile: real objects & 30 & $28(93)$ \\
Verbal & 30 & $23(77)$ \\
Pantomime of use & 30 & $24(80)$ \\
Object use & 122 & $3(2.5)$ \\
Line drawings of objects & 42 & $24(57)$ \\
Line drawings of actions & & \\
\hline
\end{tabular}

impaired in object recognition on visual presentation.

Two experiments were conducted to verify the potential dissociation between object and action naming on static visual presentation.

The first experiment required recognition of line drawings of objects $(n=122)$ taken from the Snodgrass and Vanderwart set. ${ }^{18}$ The drawings were presented on a screen $(25 \times 19$ $\mathrm{cm})$ connected to a microcomputer. Each drawing was displayed in the middle of the screen and remained there until a response was given, after which it disappeared. The screen was blank for 10 seconds between presentations. The stimuli included tools, fruits, vegetables, and animals.

The second experiment involved retrieving an action verb when looking at a line drawing depicting that action $(n=42)$. The line drawings of the actions were presented under the same conditions as the line drawings of the objects. Each drawing was obtained by modifying a black and white photograph using Adobe Photoshop ${ }^{\mathrm{TM}} 2.5 .1$ software. The final drawing essentially retained the contour of the picture and a few details (example in fig 2).

As shown in the table, the patient's ability to name actions when looking at the corresponding line drawings was markedly different from his ability to name line drawings of objects taken from the Snodgrass and Vanderwart set $\left(\chi^{2}=67.9, p<0.001\right)$. These findings indicate that the severity of this patient's visual perception deficit depends on the type of stimulus being recognised.

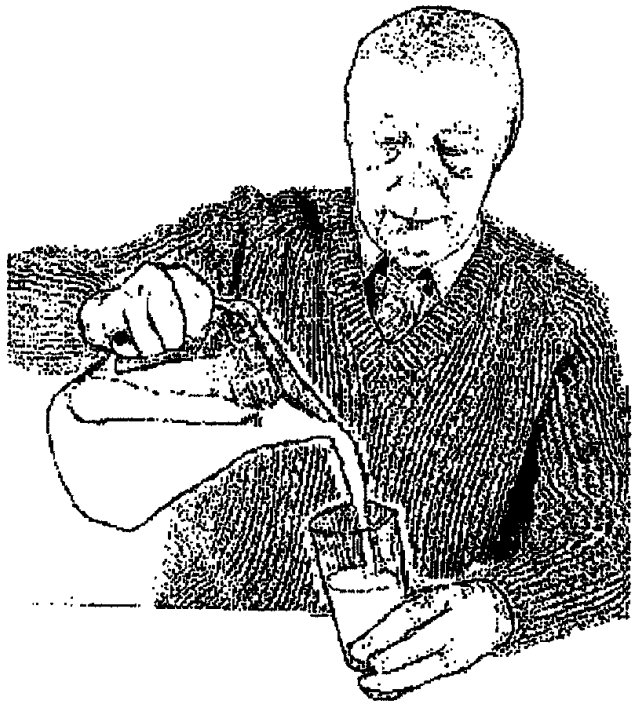

Figure 2 Example of an action line drawing correctly identified by the patient.
The line drawings of objects from the Snodgrass and Vanderwart set and the black and white photographs corresponding to an action were presented to a group of 17 normal subjects matched by age and educational level to the patient. The experimental conditions were the same as those used for the patient. Vocal response time was directly recorded by the computer with a microphone linked to it. For this group, the vocal response time recorded for verb evocation ( $t=1447 \mathrm{~ms}$ (SD 1008)) was significantly longer than it was for object name evocation ( $t=1244 \mathrm{~ms}$ (SD 868)) (repeated measurement analysis of variance (ANOVA) $F(1,96)=8.0, \mathrm{p}<0.01)$. This suggests that, for the control group, verb evocation was not easier than object name evocation. Nevertheless, with such a task, we cannot determine which level(s) of visual information processing and/or name evocation is (are) responsible for the significant differences obtained in the response time of the control group. Note also that even when the patient's ability to recognise a line drawing of an action was compared with that of a real object, action recognition was significantly better $\left(\chi^{2}=8.2\right.$, $\mathrm{p}<0.01)$.

\section{Discussion}

The patient had apperceptive visual agnosia after a bilateral occipitotemporal lesion which partially spared the primary visual cortex (fig 1). He exhibited a deficit in recognising real objects presented visually and object line drawings. This deficit is accompanied by a visual perception disorder characterised by a piecemeal, line by line copying strategy, and impairment in matching objects from different views and performing an object decision task. By contrast, he was able to name objects on tactile presentation and verbal definitions, showing that the deficit solely concerned visual input. Moreover, he was able to recognise actions shown in line drawings, in addition to objects from pantomimes depicting how they are used (table).

This case is of particular interest because the patient was able to recognise actions presented in line drawings and objects the use of which is pantomimed by the examiner. His ability to recognise action drawings should be a consequence of the extracontextual information contained in this type of stimulus compared with object drawings. In a case study of a patient with apperceptive visual agnosia, Riddoch and Humpreys (1987) ${ }^{20}$ showed that their patient was better at identifying objects when paired with an appropriate context than when shown in isolation. Such a finding suggests that semantic information can be used to decide between alternative interpretations of visual input. Nevertheless, when the scene context was given along with two visually similar objects, the results did not differ from those of isolated object identification. This suggests that visual object identification is sensitive to the effects of context, but, as those authors claim, "contextual input does not override an early deficit in the integration of visual form". Therefore, extracontextual input of action line 
drawings might facilitate recognition of the action, but it remains undetermined whether context is the main cause of the patient's good performance on action drawing recognition.

An alternative way of interpreting the patient's preserved ability to recognise actions presented in line drawings and objects the use of which is pantomimed by the examiner, and the patient's impaired ability to recognise visually presented objects, would be that the visual pathways required to perceive actions are different from those required to perceive objects. Over the past 20 years, many different visual areas have been described. In 1982, Mishkin and Ungerleider ${ }^{2}$ distinguished two visual cortical pathways. The occipitotemporal stream was shown to be mostly involved in object identification, whereas the occipitoparietal pathway was shown to be implicated in the spatial localisation of visual stimuli. Later, the occipitoparietofrontal pathway was found to be involved in visually guided movements ${ }^{6}$ and especially in grasping ${ }^{7}$ movement perception, ${ }^{8}$ visuospatial working memory, ${ }^{910}$ and recognition of a goal oriented action. ${ }^{11-14}$ The present findings suggest the involvement of the occipitoparietofrontal pathway in the visual perception of hand and body position and movement.

It was recently shown in monkeys that a group of F5 neurons (region considered to be the homologue of the caudal part of the human inferior frontal gyrus ${ }^{21}$ ) responds selectively to the sight of actions carried out by others. ${ }^{13}$ It is important to note that the main cortical input of F5 comes from anterior intraparietal area $7 \mathrm{~b},{ }^{22}$ where a neuron coding action has been reported. ${ }^{23}$ Frontal neurons selectively responding to the sight of actions were also described in humans by Fadiga $e t ~ a l^{11}$ and Rizzolatti et al. ${ }^{12}$ These authors suggest the existence of a system that matches action observation and execution, and suspect that the motor system is not devoted solely to the production of movements but is also involved in their recognition. Therefore, we speculate that the patient was able to identify objects from a gesture illustrating their use because this type of visual information is processed in the occipitoparietofrontal stream.

Studies on patients with ideomotor apraxia after parietal lesion support this hypothesis. ${ }^{24}$ Such patients, who are unable to make symbolic gestures or act out the use of an object on verbal request or imitation, are sometimes also incapable of recognising a correctly produced gesture given a stationary (photograph) or moving visual presentation. Other studies ${ }^{25}$ have shown that these patients are also unable to use the mental reconstruction of a gestural image to predict the amount of time it would take to make finger movements and visually guided pointing gestures, compared with normal subjects and patients with a lesion in the primary motor area. These findings thus suggest that the neural network involved in gestural programming is also involved in gesture recognition and mental reconstruction.

The results obtained in the present study, in which the patient's impairment in visually rec- ognising static objects contrasts with his preserved ability to recognise objects from gestures illustrating their use and to recognise actions shown in line drawings, suggest that the occipitoparietofrontal pathway is involved in conscious visual perception and in the interpretation of goal oriented actions, even when shown in a static way.

We are very grateful to the patient and his wife, who have always made the testing a pleasure. Also we extend our thanks to Yves Tocquer for his technical assistance. This work was supported by a grant to CTF from the "Institut de la Maladie by a grant to CTF from the "Institut de la Maladie
d'Alzheimer" in France. A subset of these data was presented at d'Alzheimer" in France. A subset of these data was presented at
the XXVI International Congress of Psychology, Montreal, August 1996.

1 Lissauer $\mathrm{H}$. Ein fall von seelenblindheit nebst einem Beitrage zur Theori derselben. (A case of visual agnosia with a contribution theory.) Archiv für Psychiatrie und Nervenkrankheiten 1890; 21:222-70.

2 Ungerleider LG, Mishkin M. Two cortical visual systems. In:Ingle DJ, Goodale MA, Mansfield RJW, eds. Analysis of visual behavior. Cambridge, MA: MIT Press 1982:549-86.

3 Fujita I, Tanaka K, Ito M, et al. Columns for visual features of objects in monkey inferotemporal cortex. Nature 1992;360:343-6.

4 Gross CG. Representation of visual stimuli in inferior temporal cortex. Philos Trans $R$ Soc London B Biol Sci 1992;335:3-10

5 Sergent J, Ohta B, McDonald B. Functional neuroanatomy of face and object processing: a positron emission tomography study. Brain 1992;115:15-36.

6 Goodale MA, Milner AD. Separate visual pathways for perception and action. Trends Neurosci 1992;15:20-5.

7 Jeannerod M, Arbib MA, Rizzolatti G, et al. Grasping objects: the cortical mechanisms of visuomotor transforobjects: the cortical mechanisms of visuon
mation. Trends Neurosci 1995;18:314-20.

8 Zeki S, Watson JDG, Lueck CJ, et al. A direct demonstration of functional specialization in human visual cortex. $7 \mathrm{Neu}$ rosci 1991;1:641-9.

9 Smith EE, Jonides J, Koeppe RA, et al. Spatial versus object working memory: PET investigations. Fournal of Cognitive Neuroscience 1995;7:337-56.

10 Teixeira Ferreira C, Vérin M, Pillon B, et al. Spatio-temporal working memory and frontal lesions in man. Cortex 1998;34:83-98.

11 Fadiga L, Fogassi L, Pavesi G, et al. Motor facilitation during action observation: a magnetic stimulation study. $\mathcal{f}$ Neurophysiol 1995;73:2608-11.

12 Rizzolatti G, Fadiga L, Matelli M, et al. Localization of grasp representations in humans by PET:1. Observation versus execution. Exp Brain Res 1996;111:246-52.

13 Gallese V, Fadiga L, Fogassi L, et al. Action recognition in the premotor cortex. Brain 1996;119:593-609.

14 Teixeira Ferreira C, Giusiano B, Ceccaldi M, et al. Optic aphasia: evidence of the contribution of different neural systems to object and action naming. Cortex 1997;33:499513.

15 Martin A, Haxby JV, Lalonde FM, et al. Discrete cortical regions associated with knowledge of color and knowledge of action. Science 1995;270:102-5.

16 Daniele A, Giustolisi L, Silveri MC, et al. Evidence for a possible neuroanatomical basis for a lexical processing of nouns and verbs. Neuropsychologia 1994;32:1325-41.

17 Warburton E, Wise RJS, Price CJ, et al. Noun and verb retrieval by normal subjects:Studies with PET. Brain 1996; 119:159-79.

18 Snodgrass JG, Vanderwart M. A standardized set of 260 pictures: norms for naming agreement, image agreement, pictures: norms for naming agreement, image agreement, Psychology: Human Learning and Memory 1980;6:174-215.

19 Kroll JF, Potter MC. Recognizing words, pictures and concepts: a comparision of lexical, object, and reality decisions. Fournal of Verbal Learning and Verbal Behavior 1984;23:39-66.

20 Riddoch MJ, Humphreys GW. A case of integrative visual agnosia. Brain 1987;110:1431-62.

21 Petrides M, Pandya DN. Comparative architectonic analysis of the human and the macaque frontal cortex. In: Boller F, Spinnler H, Hendler JA, eds. Handbook of neuropsychology. Spinnler H, Hendler JA, eds. Handbook
Vol 9. Amsterdam: Elsevier 1994:17-58.

22 Cavada C, Goldman-Rakic PS. Posterior parietal cortex in rhesus monkey: II. Evidence for segregated corticocortical networks linking sensory and limbic areas with the frontal lobe. F Comp Neurol 1989;287:422-45.

23 Leinonen L, Hyvärinen J, Nyman G, et al. I. Functional properties of neurons in lateral part of associative area 7 in awake monkeys. Exp Brain Res 1979;34:299-320.

24 Heilman KM, Rothi LJ, Valenstein E. Two forms of ideomotor apraxia. Neurology 1982;32:342-6.

25 Sirigu A, Duhamel JR, Cohen L, et al. The mental representation of hand movements after parietal cortex damage. Science 1996;273:1564-8. 